\title{
THE ANTIBIOTIC RESISTANCE PATTERN AND MOLECULAR CHARACTERIZATION OF blaCTX AND blaTEM GENES OF E. coli ISOLATED FROM DIFFERENT HOSTS BASED ON THE RATE OF ANTIBIOTIC CONSUMPTION IN SULAYMANIYAH/IRAQ
}

\author{
AlaA, A. R. ${ }^{1}-$ SOlHAN, M. A. ${ }^{1}-$ LALAN, R. M. ${ }^{1}-$ HiWA, L. I. ${ }^{1}-$ MHAMAD, N. R. ${ }^{1}-$ NiGA, \\ KH. M. ${ }^{1}$ - AWAT, J. N. ${ }^{1}-$ SAlAR, A. I. ${ }^{2}-$ BRWA, HR. Q. ${ }^{3}-$ DARYAN, K. KH. ${ }^{2}-$ TAIB, A. Hs. ${ }^{*}$ \\ ${ }^{1}$ Medical Laboratory department, Technical College of Health, Sulaimani polytechnic \\ university, Sulaimani/Iraq \\ ${ }^{2}$ Nursing department, Technical College of Health, Sulaimani polytechnic university, \\ Sulaimani/Iraq \\ ${ }^{3}$ Anethesia department, Technical College of Health, Sulaimani polytechnic university, \\ Sulaimani/Iraq \\ ${ }^{*}$ Corresponding author \\ e-mail: taib.ahmed@spu.edu.iq \\ (Received $20^{\text {th }}$ Feb 2020; accepted $9^{\text {th }}$ Jul 2020)
}

\begin{abstract}
Inappropriate use of antibiotics causes the emergence of multidrug resistant bacteria. Therefore, this study investigated the rate of beta- lactamase resistance genes and drug resistance pattern of $87 \mathrm{E}$. coli isolated from feces of different hosts. The rate of resistance to amoxicillin, cefotaxim, ceftriaxone, and meropenem were the highest in E. coli of humans compared to other hosts. 18 (20.6\%) isolates were positive with blaCTX-M and blaTEM and $17(19.5 \%)$ of them were found in heavy antibiotic users, but only one blaCTX-M gene (1.1\%) was discovered in the low antibiotic user group of pigeons. The rate of blaCTX-M gene was the highest in E. coli isolated from the feces of humans, 13.7\%, whereas the highest rate of blaTEM was found in E. coli of poultry, 3.4\%. The highest rate of blaCTX-M and blaTEM genes were recorded in phylogenetic groups B2 and D at the rate of $61.5 \%$ and $60 \%$, respectively. There were sequence similarities between local and foreign beta-lactamase genes, but single nucleotide polymorphism was found in comparison to CTX-M3 isolated in Poland. We conclude that $E$. coli isolated from humans were more resistant to antibiotics compared to other hosts and the rate of CTX$\mathrm{M}$ gene was more common in human hosts.
\end{abstract}

Keywords: ESBLs, antibiotic resistance, human, animal and birds

\section{Introduction}

The emergence and spread of multidrug resistant bacteria is on the rise and becoming a real threat to the global public health. Failure of treatment increases morbidity and mortality due to development of resistance to previously effective drug by bacteria (Garcia, 2014). The indiscriminate use of antibiotics is the main reason leading to the increased resistance in bacteria and this has been seen in both humans and animals (Collignon et al., 2013; Chantziaras et al., 2014). Domestic animals, including poultry, have been used as a source of food by humans from ancient times, but it has been considered as one of the potential sources of delivering bacteria carrying beta lactamase resistance genes to humans. This leads to colonization of bacteria in the gut of humans after consuming contaminated meat or gaining bacteria by direct or indirect contact with animals and eventually causing severe infections (Lazarus et al., 2015). 
Escherichia coli (E. coli) is a gram negative facultative anaerobic bacteria and belongs to the family of Enterobacteriaceae (Sorum and Sunde, 2001). These bacteria are mostly found in intestinal tract of humans and animals as part of the normal flora. $E$. coli strains cause different diseases in humans including gastrointestinal infection, urinary tract infection and neonatal meningitis (Todar, 2007). E. coli causes food poisoning in humans after consumption of contaminated food by producing lethal toxins that could lead to gastroenteritis. Pathogenic E. coli stains are classified into different types based on their virulence properties and serological characteristics (Todar, 2007; Martinez-Medina and Garcia-Gil, 2014). Enteropathogenic E. coli (EPEC) is a strain of E. coli found in both humans and some other types of animals like dogs, cats, rabbits, and horses. It causes watery diarrhea after producing an adhesion toxin (intimin) which has the ability to bind intestinal cells leading to cell deformities. This variant type of $E$. coli is moderately invasive and stimulates an inflammatory response. Enterotoxigenic $E$. coli (ETEC) strain is found to be implicated in the watery diarrhea in humans especially children in the developing countries and in animals such as sheep, goats, pigs, dogs, cattle, and horses. This strain is not invasive and lodges locally in the lumen of the intestine (Croxen et al., 2013). Enteroinvasive E. coli (EIEC) is a variant causing diarrhea only in humans. The patients characteristically have a profuse diarrhea with or without blood and high fever. Enterohemorrhagic E. coli (EHEC) strain results in bloody diarrhea with the ability to infect urinary tract and causes acute kidney failure: hemolytic uremic syndrome. It is moderately invasive and produces Shiga toxin that can cause severe inflammatory response. This strain was discovered in both humans and animals (cattle and goats) (Rendón et al., 2007). Enteroaggresive E. coli (EAEC) is a noninvasive variant of $E$. coli that can cause watery diarrhea only in humans and has the ability to produce heat-stable enterotoxins (ST) and hemolysin, pore forming toxins. Adherent-Invasive E. coli (AIEC) is an invasive strain causing disease in humans and its more common in patients who have Crohn's disease. The strain is able to multiplicate intracellularly after invading intestinal epithelial cells (Martinez-Medina and Garcia-Gil, 2014).

E. coli strains are found to live in the gastrointestinal tract where they develop resistance against antimicrobial agents and able to acquire resistance genes faster than other natural microorganisms because of the selection pressure due to heavy usage of antibiotics (Van Den Bogaard and Stobberingh, 2000; EFSA, 2010). It was recently revealed that propagation of extended spectrum $\beta$-lactamases (ESBL) is very rapid with blaCTX, one of the common ESBLs, now discovered in different parts of the world. In addition to humans and domestic animals, this resistance gene has been recovered in wild animals and birds in the last few years (Livermore et al., 2007; Coque et al., 2008; Guenther et al., 2010; Pinto et al., 2010; Veldman et al., 2013). Proliferation of this resistance gene in wildlife creates global public health threat at an alarming level. Wild birds attract the attention of the researchers because of their potential roles in transmitting diseases and becoming carriers of bacteria to humans. In addition, wild birds harboring E. coli in their intestinal tracts can become a source of dissemination of resistant bacteria (Benskin et al., 2009; Wasiński et al., 2013).

In Iraq, many studies have been conducted to isolate bacteria with resistance genes from human patients, but there are scarce studies on wildlife and free animals including birds. This study focused on a comparative study to investigate and compare the rates of antibiotic-resistant $E$. coli with beta lactamase resistance genes in three classes of antibiotic users. First group was categorized as heavy antibiotic consumers: humans and chicken of 
the poultry houses because of their chronic exposures to antibiotics. Second group was categorized as intermediate antibiotic consumers: free pastured domestic animals and free ranging chickens because of their limited access to antibiotics and the last group was categorized as non-antibiotic users; such as free living birds including sparrows, singing birds, pigeons, and wild animals like turtles, wild rabbits and hedgehogs.

\section{Materials and methods}

\section{Sample collection and bacterial isolation}

A total of 87 E. coli strains were isolated from fresh stool of humans, animals and birds as follows: Humans (healthy) 10 (E1-E10), human patients (diarrhea and UTI) 12 (E11-E22), chicken of poultry houses 11 (E23-E33), free pastured domestic animals 10 (E34-E43), free ranging poultry 14 (E44-E57), wild animals (rabbit, hedgehog, and turtle) 10 (E58-E67), sparrows 8 (E68-E75), pigeons 12 (E76-87) (Table 1 and Table 2). The sample collection was carried out between August and September 2019 in Sulaimani province. One gram of every sample was homogenized with $500 \mu 1$ of normal saline in a clean container and the mixture was swabbed on selective media, MacCkonkey agar, and incubated at $37{ }^{\circ} \mathrm{C}$ for 20 hours. A typical colony was isolated and streaked again on eosin methylene blue agar (EMB) for further purification and identification of $E$. coli. At the end, the colonies with metallic sheen green characteristic were chosen for the final confirmation by molecular biology technique using polymerase chain reaction (PCR).

Table 1. Distribution pattern of phylogenetic groups and beta lactamase resistance genes in the E. coli isolates

\begin{tabular}{c|ll|c|c|c|c|c|c}
\hline $\begin{array}{c}\text { Antibiotic (AB) } \\
\text { consumers style }\end{array}$ & \multicolumn{2}{|c|}{ Sample No. } & A & B1 & B2 & D & blaCTX & bla TEM \\
\hline \multirow{3}{*}{ Heavy AB users } & Human (Healthy) & $(10)$ & 2 & 3 & 5 & 0 & 2 & 1 \\
& Human(Patient) & $(12)$ & 0 & 4 & 5 & 3 & 10 & 1 \\
& Poultry (house) & $(11)$ & 4 & 5 & 1 & 1 & 0 & 3 \\
\hline $\begin{array}{c}\text { Intermediate AB } \\
\text { users }\end{array}$ & Poultry (Free range) & $(14)$ & 4 & 9 & 0 & 1 & 0 & 0 \\
& Domestic Animal & $(10)$ & 0 & 9 & 1 & 0 & 0 & 0 \\
\hline \multirow{3}{*}{ None AB users } & Wild Animal & $(10)$ & 0 & 8 & 2 & 0 & 0 & 0 \\
& Sparrow & $(08)$ & 0 & 8 & 0 & 0 & 0 & 0 \\
& Pigeon & $(12)$ & 0 & 9 & 2 & 1 & 1 & 0 \\
\hline & Total & $(87)$ & 10 & 55 & 16 & 6 & 13 & 5 \\
\hline
\end{tabular}

\section{Antibiotic susceptibility testing}

The antimicrobial susceptibility testing of $E$. coli isolates to six classes of beta lactam antibiotics were carried out using Kirby Bauer disc diffusion method following the protocols and guidelines recommended by the Clinical and Laboratory Standards Institute (Clinical and Laboratory Standards Institute, 2012). The antibiotics tested in this study were: amoxicillin (AX $25 \mu \mathrm{g}$ ), amoxicillin-clavulanic acid (AMC $30 \mu \mathrm{g}$ ), oxacillin (OX $1 \mu \mathrm{g}$ ), meropenem (MEM $10 \mu \mathrm{g}$ ), ceftriaxone (CRO $30 \mu \mathrm{g}$ ) and cefotaxime (CTX $30 \mu \mathrm{g}$ ) (Bioanalyse, Ankara, Turkey). 
Table 2. The resistance score of E. coli isolates

\begin{tabular}{|c|c|c|c|c|c|c|c|c|c|c|c|c|c|}
\hline No. & \begin{tabular}{c|}
$\mathbf{A X}$ \\
$\leq 13$ \\
\end{tabular} & $\begin{array}{c}\mathbf{A M C} \\
\leq 13\end{array}$ & $\begin{array}{c}\mathbf{O X} \\
\leq 10\end{array}$ & $\mathbf{M E M} \leq 13$ & $3 \mathbf{C R O} \leq 13$ & $\begin{array}{l}\text { CTX } \\
\leq 14\end{array}$ & No. & $\mathbf{A X} \leq 13$ & $\mathbf{A M C} \leq 13$ & $\begin{array}{l}\mathbf{O X} \\
\leq 10\end{array}$ & $\mathbf{M E M} \leq 13$ & $\mathbf{C R O} \leq 13$ & \begin{tabular}{|l} 
CTX \\
$\leq 14$
\end{tabular} \\
\hline E1 & 21 & 21 & 13 & 26 & 25 & 30 & E45 & 23 & 15 & 12 & 28 & 26 & 20 \\
\hline E2 & 16 & 13 & 0 & 34 & 25 & 33 & E46 & 14 & 15 & 11 & 30 & 33 & 31 \\
\hline E3 & 20 & 20 & 10 & 31 & 27 & 36 & E47 & 18 & 10 & 2 & 26 & 24 & 28 \\
\hline E4 & 24 & 19 & 0 & 30 & 24 & 29 & E48 & 20 & 16 & 11 & 30 & 27 & 28 \\
\hline E5 & 9 & 20 & 3 & 29 & 9 & 11 & E49 & 18 & 0 & 12 & 30 & 25 & 29 \\
\hline E6 & 25 & 23 & 4 & 31 & 25 & 34 & E50 & 25 & 14 & 15 & 37 & 29 & 33 \\
\hline E7 & 25 & 21 & 2 & 29 & 26 & 34 & E51 & 20 & 10 & 0 & 29 & 22 & 24 \\
\hline E8 & 24 & 21 & 8 & 30 & 25 & 35 & E52 & 21 & 14 & 14 & 29 & 25 & 27 \\
\hline E9 & 15 & 7 & 10 & 15 & 23 & 26 & E53 & 16 & 9 & 7 & 28 & 24 & 26 \\
\hline E10 & 0 & 11 & 9 & 29 & 21 & 9 & E54 & 19 & 19 & 16 & 29 & 23 & 25 \\
\hline E11 & 2 & 0 & 14 & 33 & 25 & 37 & E55 & 15 & 17 & 12 & 31 & 25 & 28 \\
\hline E12 & 15 & 0 & 11 & 28 & 20 & 11 & E56 & 20 & 15 & 17 & 25 & 19 & 25 \\
\hline E13 & 3 & 20 & 7 & 34 & 0 & 23 & E57 & 18 & 15 & 13 & 29 & 24 & 17 \\
\hline E14 & 4 & 19 & 0 & 36 & 0 & 13 & E58 & 19 & 12 & 15 & 26 & 11 & 25 \\
\hline E15 & 0 & 11 & 9 & 28 & 7 & 10 & E59 & 21 & 9 & 10 & 31 & 27 & 29 \\
\hline E16 & 8 & 13 & 1 & 33 & 13 & 17 & E60 & 14 & 7 & 14 & 27 & 23 & 25 \\
\hline E17 & 11 & 11 & 11 & 28 & 8 & 9 & E61 & 20 & 12 & 13 & 29 & 23 & 27 \\
\hline E18 & 0 & 7 & 2 & 34 & 9 & 13 & E62 & 23 & 15 & 6 & 31 & 22 & 30 \\
\hline E19 & 0 & 2 & 0 & 12 & 8 & 5 & E63 & 19 & 12 & 9 & 30 & 24 & 14 \\
\hline E20 & 0 & 19 & 15 & 33 & 7 & 15 & E64 & 20 & 11 & 7 & 31 & 24 & 26 \\
\hline E21 & 6 & 10 & 6 & 28 & 24 & 31 & E65 & 21 & 13 & 0 & 29 & 25 & 26 \\
\hline E22 & 27 & 19 & 13 & 33 & 24 & 31 & E66 & 21 & 16 & 10 & 29 & 24 & 28 \\
\hline E23 & 22 & 19 & 8 & 30 & 21 & 29 & E66 & 21 & 13 & 13 & 30 & 23 & 28 \\
\hline E24 & 13 & 0 & 10 & 35 & 26 & 32 & E68 & 22 & 11 & 7 & 29 & 24 & 26 \\
\hline E25 & 21 & 15 & 0 & 34 & 24 & 31 & E69 & 24 & 14 & 9 & 30 & 25 & 29 \\
\hline E26 & 10 & 13 & 0 & 30 & 27 & 34 & E70 & 21 & 15 & 0 & 30 & 29 & 28 \\
\hline E27 & 23 & 22 & 11 & 32 & 23 & 30 & E71 & 20 & 11 & 13 & 30 & 25 & 29 \\
\hline E28 & 8 & 11 & 9 & 31 & 23 & 32 & E72 & 20 & 12 & 0 & 29 & 31 & 30 \\
\hline E29 & 26 & 22 & 22 & 33 & 29 & 31 & E73 & 18 & 9 & 14 & 28 & 23 & 20 \\
\hline E30 & 28 & 20 & 13 & 31 & 25 & 33 & E74 & 20 & 8 & 11 & 28 & 23 & 27 \\
\hline E31 & 23 & 18 & 13 & 24 & 24 & 28 & E75 & 23 & 14 & 13 & 31 & 26 & 30 \\
\hline E32 & 22 & 14 & 9 & 29 & 26 & 13 & E76 & 14 & 12 & 11 & 30 & 0 & 16 \\
\hline E33 & 25 & 22 & 14 & 27 & 26 & 33 & E77 & 18 & 9 & 2 & 32 & 31 & 31 \\
\hline E34 & 14 & 4 & 12 & 23 & 21 & 26 & E78 & 22 & 8 & 8 & 26 & 27 & 25 \\
\hline E35 & 22 & 19 & 15 & 35 & 24 & 28 & E79 & 13 & 12 & 16 & 30 & 23 & 28 \\
\hline E36 & 15 & 7 & 7 & 34 & 24 & 29 & E80 & 20 & 17 & 9 & 29 & 23 & 29 \\
\hline E37 & 23 & 13 & 0 & 34 & 32 & 30 & E81 & 20 & 11 & 12 & 25 & 23 & 25 \\
\hline E38 & 21 & 17 & 1 & 26 & 22 & 35 & E82 & 19 & 16 & 11 & 26 & 21 & 28 \\
\hline E39 & 23 & 19 & 0 & 30 & 24 & 27 & E83 & 22 & 10 & 18 & 32 & 27 & 29 \\
\hline E40 & 22 & 20 & 13 & 30 & 24 & 31 & E84 & 19 & 15 & 8 & 30 & 27 & 28 \\
\hline E41 & 25 & 14 & 0 & 29 & 29 & 32 & E85 & 26 & 24 & 13 & 34 & 26 & 14 \\
\hline $\mathbf{E 4 2}$ & 7 & 11 & 15 & 37 & 28 & 33 & E86 & 8 & 10 & 12 & 22 & 24 & 30 \\
\hline E43 & 19 & 15 & 2 & 31 & 20 & 15 & E87 & 14 & 13 & 1 & 27 & 9 & 8 \\
\hline E44 & 12 & 16 & 11 & 28 & 20 & 15 & & & & & & & \\
\hline
\end{tabular}

The resistance score of the isolates were highlighted in red color. The number behind the " $\leq$ " is the inhibition zone in $\mathrm{mm}$ for the resistance zone. The tested antibiotics were amoxicillin (AX $25 \mu \mathrm{g}$ ), amoxicillin-clavulanic acid (AMC $30 \mu \mathrm{g}$ ), oxacillin (OX $1 \mu \mathrm{g}$ ), meropenem (MEM $10 \mu \mathrm{g}$ ), ceftriaxone $(\mathrm{CRO} 30 \mu \mathrm{g})$ and cefotaxime (CTX $30 \mu \mathrm{g})$ 


\section{Molecular biological methods}

\section{DNA extraction}

Total DNA of E. coli was extracted by boiling fresh colonies grown on nutrient media. The boiling was carried out by dissolving one single colony in $150 \mu \mathrm{l}$ sterilized distilled water in a micro tube and then the mixture was heated at $99.9{ }^{\circ} \mathrm{C}$ on a heating block for 15 minutes (Dashti et al., 2009). The mixture was allowed to precipitate at room temperature and the supernatant containing DNA was used for PCR.

\section{E. coli confirmation and phylogenetic grouping}

Beta-glucuronidase (uidA) gene was used to confirm E. coli via PCR amplification of its flanking region. If no $E$. coli isolate harbor (uidA) gene, an attempt was made to amplify a second specific $E$. coli marker gene, the universal stress protein (uspA). This PCR identification confirmation of $E$. coli was carried out according to Chen and Griffiths, 1998; Heijnen and Medema, 2006; Godambe et al., 2017).

This study used the protocol according to Bonacorsi et al. (2000) to determine a phylogenetic grouping of $E$. coli with some modifications in PCR reactions. The grouping depends on finding and amplifying three genes: the chuA, yjaA and DNA fragment TSPE4.C2. Two of the genes, the chuA and yjaA, were amplified using duplex conventional PCR, but DNA fragment TSPE4.C2 was amplified via singleplex PCR.

\section{Polymerase chain reaction of blaCTX-M and blaTEM-1}

Two common extended spectrum beta lactamase resistance genes (ESBLs), blaCTX-M (550 bp) and blaTEM-1 (1080 bp) (Bradford, 2001) were amplified. Duplex PCR was used to amplify both genes. The primers and protocols used were according to Ahmed et al. (2007, 2009).

\section{PCR condition and Gel electrophoresis}

All PCR reactions in this study including multiplex and singleplex were carried out in PCR tubes composed of $20 \mu \mathrm{l}$ volume of reaction mixture. The volume was prepared by adding $2 \mu \mathrm{l}$ of DNA template of each isolate into a mixture containing $10 \mu \mathrm{l}$ of $2 \mathrm{X}$ premix RedTaq DNA polymerase (SBS Genetech, Beijing, China), each primer with a concentration of $0.25 \mu \mathrm{M}$ and the final volume attained with distilled water. The following conditions were used to run PCR using applied biosystem thermo cycler (Applied biosystem 2720, California, USA): The run started with $94{ }^{\circ} \mathrm{C}$ for $5 \mathrm{~min}$, the run continued with 35 cycles of three different temperatures $\left(94{ }^{\circ} \mathrm{C} 30 \mathrm{sec}, 55^{\circ} \mathrm{C} 30\right.$ sec, $72{ }^{\circ} \mathrm{C} 30 \mathrm{sec}$ ), and finally the PCR reaction was ended with last temperature condition of $72{ }^{\circ} \mathrm{C}$ for 7 minutes.

Gel electrophoresis was carried out through running PCR products on DNA agarose gels (2\% for phylogenetic grouping genes and $1 \%$ for the other genes) at $100 \mathrm{~V}$ for 30 minutes. The resolved genes and DNA ladders were visualized under blue light using SmartDoc 2.0 Imaging System (Accuris, NJ, USA) after staining with fluorescent dye, GoodView (SBS Genetech, Beijing, China). 


\section{Sequence analysis}

The PCR products of CTX-M genes were gel recovered and purified using gel extraction purification kit (SBS Genetech, Beijing, China). The purified Products were sequenced using Sanger sequencing on ABI 3730XL capillary machine (CHU de Québec-Université Laval, Québec city, Canada). All sequences of this study were submitted to the GenBank National Center for Biotechnology Information (NCBI) via Bankit (Benson et al., 2015) and obtained accession numbers (MN597105-MN597117).

The obtained sequences were aligned to available sequences of CTX-M gene in Genbank using NCBI BLASTn search tool (http://www.ncbi.nlm.nih.gov/). The multisequence alignment of the sequences of this current study and those sequences available in the GenBank was carried out using ClustalW multi alignment tool. Phylogenic tree was drawn for all our sequences and retrieved sequences of the GenBank using the neighbor-joining (NJ) method (Phylogeny.fr) (Dereeper et al., 2010).

\section{Results}

\section{Isolation and phylogenetic grouping}

Eighty-seven (87) E. coli isolates were recovered from the different categories of antibiotic users in order to compare the drug resistance pattern to the antibiotics and the rate of the resistance genes. The $E$. coli isolates were recovered using conventional culture method and genetically confirmed using molecular biology techniques. E. coli gene marker, beta-glucuronidase (uidA $201 \mathrm{bp}$ ) was used for the final confirmation. The flanking region of the gene (201 bp) was amplified using E. coli specific primers (Figure 1). Out of 87 isolates, $83(95.4 \%)$ isolates were positive for uidA marker gene. Four isolates remained questionable to be $E$. coli, so the second $E$. coli marker gene, uspA was used to identify the isolates. PCR amplification of the universal stress protein (uspA 800 bp) was carried out using specific primers for E. coli uspA gene. The Four $(4.5 \%)$ remaining isolates were positive for $u s p A$ gene therefore all the isolates were confirmed to be $E$. coli.

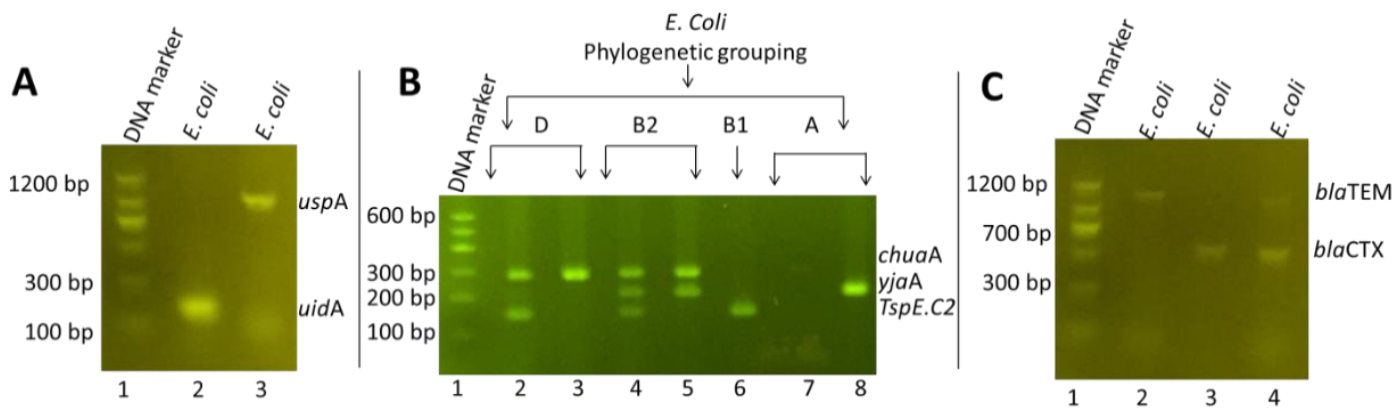

Figure 1. PCR amplification of different genes of E. coli. (A) PCR amplification of uidA and uspA genes used for the confirmation of E. coli. (B) Phylogenetic grouping* based on the different combinations of chuaA, yjaA, and TspE.C2 (Bonacorsi et al., 2000). (C) PCR amplification of beta lactamase resistance genes, blaTEM, and blaCTX. * The phylogenetic grouping was carried out in two PCR reactions, but two PCR reactions were mixed to clarify and show the combination of different genes of the groups, lane 2 and 3 
There are four main phylogenetic grouping of E. coli strains: A, B1, B2 and D. Commensal strains of E. coli belong to group A and B1 (Saralaya et al., 2015). E. coli strains in group B2 and to lesser extent group D are virulent extra-intestinal strains (Bonacorsi et al., 2000). All the $87 \mathrm{E}$. coli isolates were subjected to the phylogenetic grouping of $E$. coli based on different combinations of yjaA, chuA, and TSPE4.C2 genes. Out of the $87 \mathrm{E}$. coli isolates, group B1 was the dominant group with 55 isolates (63.2\%) followed by group B2 with 16 isolates (18.3\%) and then group A with 10 isolates (11.4\%). Group D was the least with just 6 isolates (6.8\%) (Table 1). Out of 22 isolates recovered from humans, the highest rate 10 (45.4\%) were under group B2 while the lowest rate $9 \%$ (2 isolates) was in group A. The rate of group B1 in all animals and birds was the highest at $73.8 \%$ (48 out of 65 ), but group D recorded the lowest rate at $4.6 \%$ (3 out of 65$)$.

\section{Antibiotic susceptibility testing}

$E$. coli isolates were investigated to determine their antibiotic resistance phenotype against different classes of beta lactam antimicrobials (Figure 2). The highest resistance pattern revealed in this study was to oxacillin $(1 \mu \mathrm{g}) 54.5 \%$, and the lowest resistance rate was against meropenem $(10 \mu \mathrm{g}) 1 \%$. The resistance rate of the other antibiotics was as follows: amoxicillin $(25 \mu \mathrm{g})$ 19.3\%, amoxicillin-clavulanic acid (30 $\mu \mathrm{g}) 50.3 \%$, cefotaxime $(30 \mu \mathrm{g}) 16.7 \%$., and ceftriaxone $(30 \mu \mathrm{g})$ 13\%. The resistance score of each E. coli isolates are shown in Table 2.

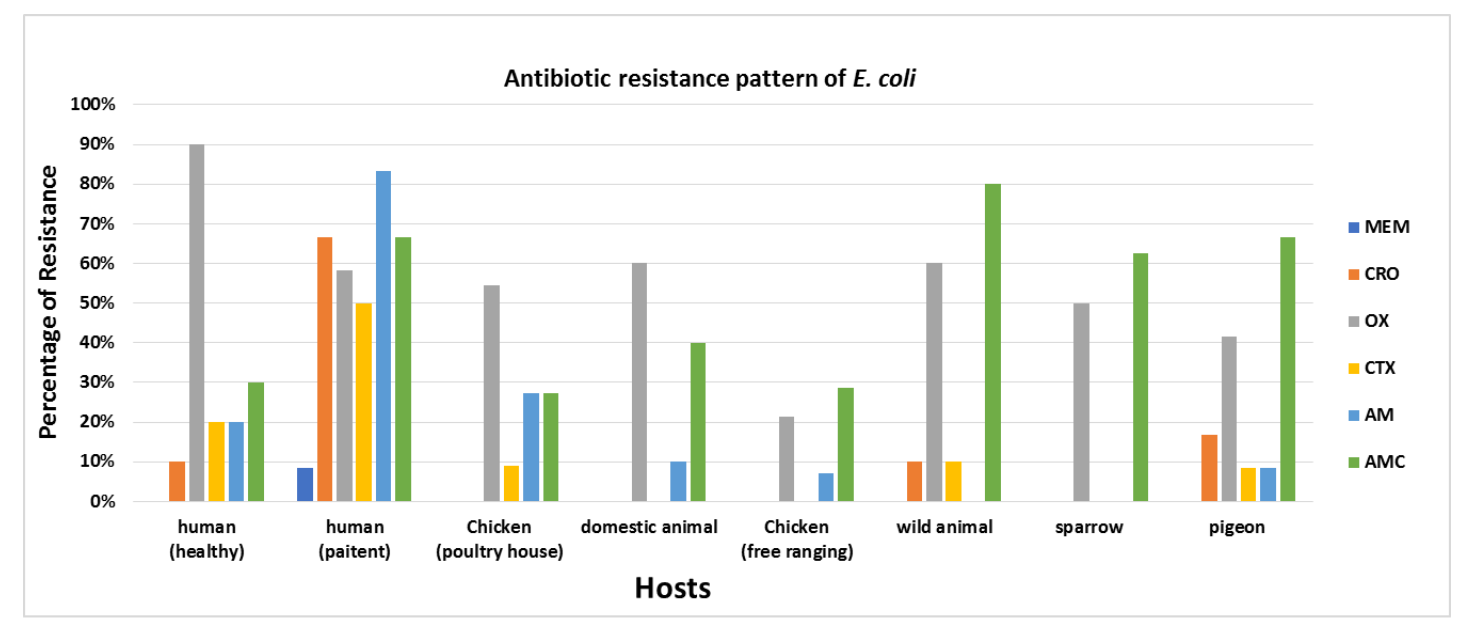

Figure 2. Antibiotic resistance pattern of E. coli isolates in different hosts

\section{Antibiotic resistance pattern of $E$. coli in different hosts}

Resistance rate to Oxacillin $(1 \mu \mathrm{g})$ was high in all different hosts compared to other antibiotics. Resistance rate was the highest in healthy humans (90\%) followed by human patients (58\%) and chicken of poultry houses $(55 \%)$, but the lowest rate was in free ranging chickens (21\%) (Figure 2). E. coli isolated from wild animals had the highest rate of resistance to amoxillin-clavulanic acid $(30 \mu \mathrm{g})(80 \%)$ among all the hosts followed by human patients $(67 \%)$ and the lowest rate was in poultry housing chicken $(27 \%)$. In human patients, the resistance rates of $E$. coli isolates to amoxicillin, ceftriaxone (30 $\mu \mathrm{g})$, cefotaxim $(30 \mu \mathrm{g})$, and meropenem (MEM $10 \mu \mathrm{g}$ ) were the highest in human patients 
compared to other hosts at the rates of $83 \%, 67 \%, 50 \%$, and $8 \%$ for the antibiotics respectively.

\section{The rate of resistance genes, blaCTX-M and blaTEM-1 genes in E. coli isolated from different hosts}

CTX-M is a class A beta-lactamase enzyme with a great activity against cefotaxime. It is believed to have evolved from two beta-lactamase enzymes, TEM and SHV after several mutations. More than 172 types of this enzyme have been found (Antonopoulos et al., 2018; Ramadan et al., 2019) and some of these enzymes are active against both ceftazidime and cefotaxime (Boyd et al., 2004; Paterson and Bonomo, 2005). This class of beta-lactamase is mostly found in E. coli and Salmonella enterica, but they are also present in other members of Enterobacteriaceae (Woodford et al., 2004; Hudson et al., 2014). In this study, a set of primers was used to amplify and sequence blaCTX-M gene in order to identify, to family level, the type of CTX-M in the area.

The amplicons of blaCTX-M (550 bp) and blaTEM-1 (1080 bp) were amplified using gene specific universal primers to determine the rate of the beta lactams resistance genes in the area of the study (Figure 2). Out of 87 samples, 18 (20.6\%) were positive for the beta lactamase resistance genes, blaCTX-M and blaTEM-1 (Table 1). The rate of blaCTX-M was remarkably higher, 13 (14.9\%) compared to blaTEM $5(5.7 \%)$ isolates (Table 1). The highest number of blaCTX resistance gene, 10 (11.1\%) was discovered in human patients, but the highest rate of blaTEM, $3(3.4 \%)$ was found in chickens of poultry houses. In total, $12(13.7 \%)$ blaCTX resistance genes were recovered in E. coli of heavy antibiotic user hosts (all in human), whereas only one resistance gene $(1.1 \%)$ was found in none antibiotic consumer hosts and none of the resistance genes were recovered from the intermediate antibiotic users.

Most of the beta lactamase genes, blaCTX-M and blaTEM were recorded in phylogenetic group B2 and D at the rate of $61.5 \%$ and $60 \%$, respectively. The highest rate of blaCTX was found in phylogenetic groups B2 and B1 at the rate of $38.4 \%$ and $30.7 \%$, followed by group D (23\%) and A (7.6\%). However, most of the blaTEM were located into group D and B1 at equal rate of $40 \%$ followed by group B2 (20\%) and none of them was recorded in group A (Figure 3).

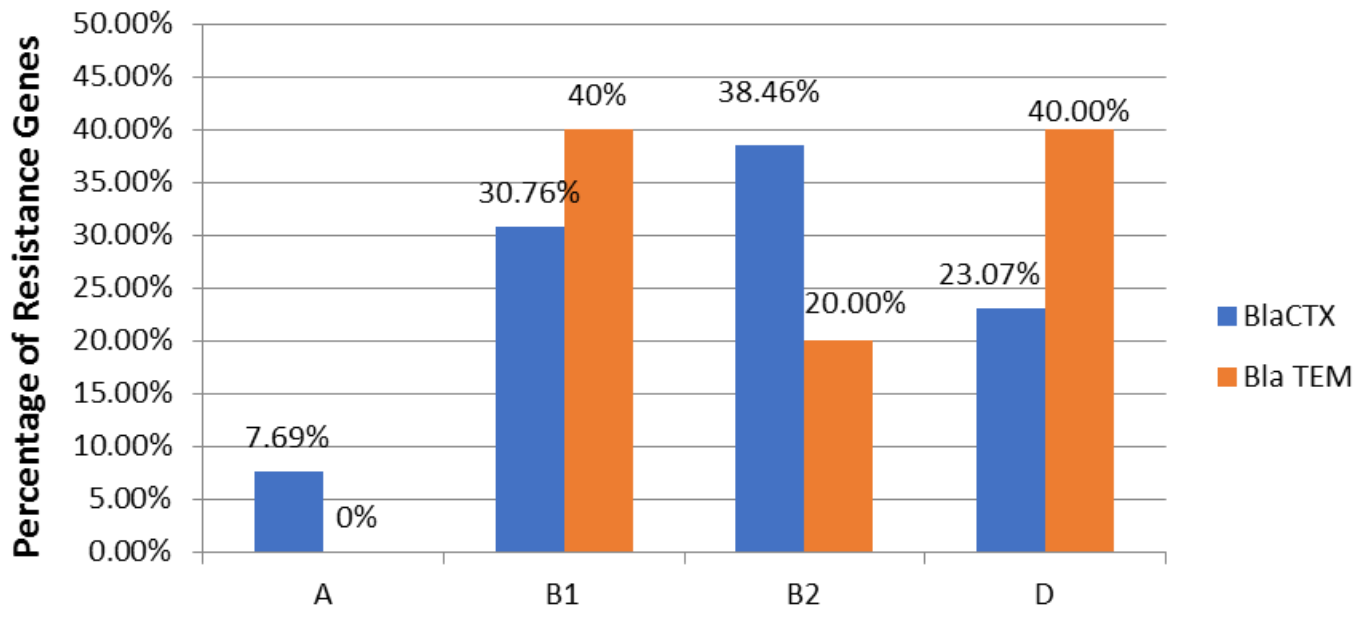

E. coli Phylogenetic groups

Figure 3. Distribution of blaCTX and blaTEM resistance genes on E. coli phylogenetic groups 


\section{Sequence analysis of blaCTX-M}

blaCTX-M genes isolated in this study were sequenced using sanger sequencing. The results from the sequencing of CTX-M genes recovered from E. coli isolates in different hosts were aligned together (Figure 4). The results showed that all the sequences were similar to one another with no mutation observed.

A

Seq1/MN597105
Seq2/MN597106
Seq3/MN597107
Seq4/MN597108
Seq5/MN597109
seq6/MN597110
Seq7/MN597111
Seq8/MN597112
Seq9/MN597113
Seq10/MN597114
Seq11/MN597115
Seq12/MN597116
Seq13/MN597117
EU556755.1/Hungary
MK590075.1/Gabon
MK576103.2/Brazil
FM213371.1/Poland

472

CTGCCTGCTTCCTGGGTTGTGGGGGATAAAACCGGCAGCGGTGGCTATGGCACCACCA CTGCCTGCTTCCTGGGTTGTGGGGGATAAAACCGGCAGCGGTGGCTATGGCACCACCA CTGCCTGCTTCCTGGGTTGTGGGGGATAAAACCGGCAGCGGTGGCTATGGCACCACCA CTGCCTGCTTCCTGGGTTGTGGGGGATAAAACCGGCAGCGGTGGCTATGGCACCACCA CTGCCTGCTTCCTGGGTTGTGGGGGATAAAACCGGCAGCGGTGGCTATG GCACCACCA CTGCCTGCTTCCTGGGTTGTGGG GGATAAAACCGGCAGCGGTG GCTATGG CACCACCA CTGCCTGCTTCCTGGGTTGTGGGGGATAAAACCGGCAGCGGTGG CTATGGCACCACCA CTGCCTGCTTCCTGGGTTGTGGGGGATAAAACCGGCAGCGGTGGCTATGGCACCACCA CTGCCTGCTTCCTGGGTTGTGGGGGATAAAACCGGCAGCGGTGG CTATGGCACCACCA CTGCCTGCTTCCTG GGTTGTG GGG GATAAAACCG GAGCGGTGG CTATG GCACCACCA CTGCCTGCTTCCTG GGTTGTGGGGGATAAAACCGGCAGCGGTGGCTATGGCACCACCA CTGCCTGCTTCCTGGGTTGTGGGGGATAAAACCGGCAGCGGTGGCTATGGCACCACCA CTGCCTGCTTCCTGGGTTGTGGGGGATAAAACCGGCAGCGGTGGCTATGGCACCACCA CTGCCTGCTTCCTGGGTTGTGGGGGATAAAACCGGCAGCGGTGGCTATGGCACCACCA CTGCCTGCTTCCTGGGTTGTGGGGGATAAAACCGGCAGCGGTGGCTATGGCACCACCA CTGCCTGCTTCCTGGGTTGTGGGGGATAAAACCGGCAGCGGTGGCTATGGCACCACCA CTGCCTGCTTCCTGGGTTGTGGGGGATAAAACCGGCAGCGGTGACTATGGCACCACCA $* * * * * * * * * * * * * * * * * * * * * * * * * * * * * * * * * * * * * * * * * * * * * * * * * * * * * * * * * * *$

$\mathbf{B}$

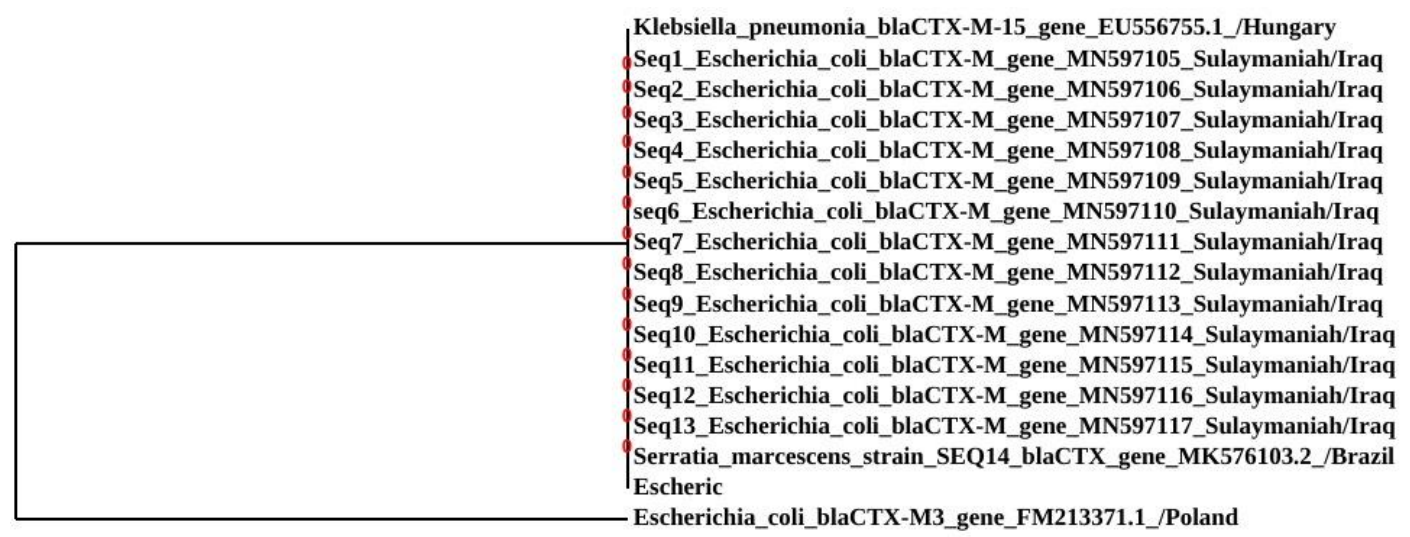

0.0008

Figure 4. Multiple sequence alignment and phylogenic tree of blaCTX-M genes recovered from E. coli and some other species. (A) CTX-M gene in E. coli strains isolated from Sulaimaniyah in comparison with published CTX-M genes of E. coli, Klebsiella pneumonia, and Serratia marcescens strains from GenBank. (B) Phylogenetic CTX-M gene in E. coli strains isolated from Sulaimaniyah in comparison with homologous published CTX-M genes in GenBank

The CTX-M gene sequences of E. coli were also compared to available sequences on GenBank using BLAST search. The sequence is completely similar to available sequences deposited in the database from other countries. But interestingly one single nucleotide difference (single nucleotide polymorphism, SNP) was revealed when CTX-M3 gene from our study was compared to that published in Poland, FM213371.1 (Figure 4). The single nucleotide polymorphism position was indicated in nucleotide number 515 as indicated in Figure 4. The phylogenetic tree showed the degree of 
similarity between local strains with that from Brazilian, Hungarian and Gabon and the SNP observed with the strain from Poland.

\section{Discussion}

To our knowledge, this is the first comparative study in Iraq to report the presence of ESBL producing $E$. coli in different antibiotic consumers, heavy antibiotic consumers, intermediate antibiotic consumers, and low antibiotic users. This study was conducted in summer 2019 between September and October. Humans and poultry houses were considered as heavy antibiotic users because they consume large amount of antibiotic for treatment and prophylaxis purposes in the area of the study due to easy access to buy antibiotic over the counter without any drug prescription. Intermediate antibiotic user was used in this study to denote those animals and birds consuming antibiotic in very rare events. Domestic animals and birds are being reared by villagers and are not using antibiotics to rear them except in very necessary cases such as in debilitating diseases. Non-antibiotic user refers to those animals and birds which are not domesticated. They live freely and they are not exposed to antibiotic because they don't have close contact with humans. In this group are wild animals (hedgehog, turtle and rabbit), sparrows and wild pigeons.

The result of this study showed a high percentage of fecal E. coli bearing blaCTX and blaTEM, $20.6 \%$ of $87 \mathrm{E}$. coli isolates isolated from feces of humans, animals and birds. Out of 18 beta lactam resistance genes, 13 (14.9\%) were blaCTX and five (5.7\%) were blaTEM. The highest rate of blaCTX genes $13.7 \%$ (12 isolates) were recovered from humans. Most of the resistance genes were found in heavy antimicrobial users, 17 out of 18 resistance genes in 87 isolates (19.5\%). The rate of resistance genes was higher in human patients $(11.1 \%)$ than in healthy humans. There were no beta lactamase resistance genes, blaCTX, and blaTEM, recorded in intermediate antibiotic users (live stocks and free living poultry) in this study. The high percentage of E. coli producing blaCTX in human feces is comparable with studies in different countries. This study is totally in agreement with the study of many countries that the rate of blaCTX is significantly high (Valentin et al., 2014). The rate of blaCTX is $0 \%$ in E. coli isolated from feces of poultry in the current study and this result is similar to the finding in many countries of Asia and Europe. In The Netherlands E. coli harboring blaCTX was recorded $0 \%$. In addition, it is comparable with the study in other countries of Europe where the prevalence of blaCTX is very low such as in Belgium (2\%), and the United Kingdom (12\%) (Smet et al., 2008; Randall et al., 2011; Huijbers et al., 2014). Same low record was investigated in Asian countries, Japan and China with low percentage of $0-2 \%$, whereas the finding is different from different studies carried out in Africa. It is concluded in many studies that the rate of blaCTX is significantly high and it is one of the most prevalent genes in live stocks and poultry (reviewed in: Alonso et al., 2017). This is however at variance to the finding in Ghana where they recorded high rate of blaCTX in poultry, 96\% (Falgenhauer et al., 2019). So the geographical distribution of blaCTX in this study area is more similar to Asia and Europe and it is the opposite to that of Africa.

For non-antibiotic consumers (wild animals, pigeon, and sparrow) also the lowest prevalence rate of beta lactamase resistance genes was recorded. From the E. coli isolated from feces of 30 animals and birds, only one (1.1\%) E coli isolate producing blaCTX gene was recovered in pigeon and there was not any blaTEM recorded in this 
category of animals. Comparative study of E. coli bearing ESBL in wild birds is not similar in different countries on the same continent. In Europe, the prevalence is very high in some countries while it is very low in others. The rate of blaCTX is $0 \%$ and $0.7 \%$ in Denmark and Poland, respectively, which is more similar to our results. Similar studies showed that prevalence rate was relatively higher in African, Tunisia (10.8\%), and in some other countries of Europe (Guenther et al., 2012; Veldman et al., 2013; Alcalá et al., 2016; Ben Yahia et al., 2018). But the rate is much higher in some countries of Europe, in The Netherland (37.8\%) and in Spain 74.8\% (Stedt et al., 2015).

Sequence analysis of CTX-M revealed that all CTX-M gene sequences recovered in $E$. coli isolates in this study from different hosts were similar depending on multiple sequence alignment and phylogeny tree. Among all the hosts except for humans, only one CTX-gene was discovered in E. coli of pigeon (MN597117) and it had 100\% sequence similarity with CTX genes of E. coli isolated from humans (MN597105MN597116) (Figure 4). The local sequences were then compared to published CTX-M genes of the same strain and other species of bacteria found in the GenBank. The local sequences showed $100 \%$ sequence similarities with sequences found in Brazil (MK576103.2), Hungary (EU556755.1), and Gabon (MK590075.1), but there was one nucleotide change in the CTX-M3 found in Poland (FM213371.1) and this difference can be seen in phylogenic tree and multiple sequence alignment in Figure 4.

Distribution of $E$. coli phylogenetic groups on different categories of antibiotic consumers carried out in this study. The result showed that the highest rate of heavy antibiotic users was categorized under phylogenetic group B1, 13.7\% and B2, 12.6\%, while the lowest rate was in group A, 6.8\%. Both groups of intermediate and low antibiotic users recorded high rate categorization under group B1 with the rate of 49.4\%. Most of the beta lactamase genes, blaCTX-M and blaTEM were recorded in phylogenetic group $\mathrm{B} 2$ and $\mathrm{D}$ at the rate of $61.5 \%$ and $60 \%$, respectively, and the highest rate of blaCTX was found under phylogenetic group of $\mathrm{B} 2,38.4 \%$. This result is comparable with published conclusion that most pathogenic E. coli belong to phylogenetic groups B2 and D and these two groups were prevalent in those human patients who are heavy antibiotic users (Bingen et al., 1998).

Antibiotics have been hitherto effective antibacterial agents used to treat bacterial infection in the field of human and veterinary medicine. Ability of bacteria to produce resistance against antibiotics impedes or delays the treatment which results in economic losses and even morbidity (Grover et al., 2013). In addition, wild birds can become a source of spreading resistant bacteria from one area to another especially to humans (Peirano et al., 2011). Therefore, this comparative study investigated the drug resistance pattern differences between high to low antibiotic users. The multidrug resistance and drug resistance pattern of these tested antibiotics in E. coli is significantly important because beta-lactam antibiotics (cephalosporins) especially meropenem (new generation) are known as the frontline antibiotics for the treatment of bacterial infection (Bradford, 2001). Furthermore, bacteria harboring blaCTX and blaTEM resistance genes become resistant against different classes of beta-lactam antibiotics (Boyd et al., 2004; Paterson and Bonomo, 2005). Therefore, six beta-lactam antibiotics were chosen to investigate the resistance phenotype of $E$. coli in this study, amoxicillin $(25 \mu \mathrm{g})$, amoxicillin-clavulanic acid $(30 \mu \mathrm{g})$, oxacillin $(1 \mu \mathrm{g})$, meropenem $(10 \mu \mathrm{g})$, ceftriaxone $(30 \mu \mathrm{g})$ and cefotaxime $(30 \mu \mathrm{g})$.

The rate of antibiotic resistance was higher in E. coli isolated from heavy antibiotic users than in other groups in this study against amoxicillin $(25 \mu \mathrm{g})$, amoxicillin- 
clavulanic acid $(30 \mu \mathrm{g})$, oxacillin $(1 \mu \mathrm{g})$, meropenem $(10 \mu \mathrm{g})$, ceftriaxone $(30 \mu \mathrm{g})$ and cefotaxime $(30 \mu \mathrm{g})$ (Figure 2) and followed by wild animals against oxacillin and amoxicillin-clavulanic acid which showed relatively high resistance. In total, the resistance percentage to oxacillin was the highest and the sensitivity against meropenem was remarkably high in all E. coli isolates in this study. 29 (33.3\%) out of 87 isolates showed multidrug resistance to different antibiotics especially against different antibiotics and the highest rate of multidrug resistance was in heavy antibiotic user group, $15(17.2 \%)$. This multidrug resistance were comparable in different studies in different countries (Forward et al., 2004; Yan et al., 2004; Sunde, 2005; Ahmed et al., 2009; Hansen et al., 2013). E. coli isolates bearing blaCTX showed resistance to extended spectrum antibiotic, cefotaxim. This finding is consistent with some studies in different countries, Ghana, (Hackman et al., 2014), Ethiopia (Zeynudin et al., 2018) and India (Upadhyay et al., 2015) that most bacteria harboring CTX-M resistance genes are resistant to third generation of cephalosporin.

\section{Conclusion}

This study revealed a remarkably high rate of blaCTX in E. coli isolated from different hosts and it is obviously more predominant in heavy antibiotic user hosts (humans) in Sulaimani region/Iraq. blaCTX and blaTEM were mostly found in phylogenetic groups B2 and D. Pathogenic E. coli isolated from human patients showed higher degree of resistance to antibiotics compared to other hosts. Meropenem $(10 \mu \mathrm{g})$ antibiotics remains the most active against $E$. coli in all hosts. So E. coli living in the intestinal tract of domestic animal, free living poultry, free living flying birds and wild lives are less resistant to antibiotics and less often carry beta lactam resistance genes compared to human. Therefore, those animals and birds do not pose a big threat and risk to human public health in this study area.

Acknowledgements. We acknowledge the president of Sulaimani Polytechnic University and especially Assistant Professor Dr. Alan Faraydoon Ali for his great help and academic support to perform this research. Also, we would like to appreciate Mam Humanitarian Foundation for their financial and logistic support.

\section{REFERENCES}

[1] Ahmed, A. M.. Motoi, Y., Sato, M., Maruyama, A., Watanabe, H., Fukumoto, Y., Shimamoto, T. (2007): Zoo animals as reservoirs of gram-negative bacteria harboring integrons and antimicrobial resistance genes. - Applied and Environmental Microbiology 73(20): 6686-6690. doi: 10.1128/AEM.01054-07.

[2] Ahmed, A. M., Shimabukuro, H., Shimamoto, T. (2009): Isolation and molecular characterization of multidrug-resistant strains of escherichia coli and salmonella from retail chicken meat in Japan. - Journal of Food Science 74(7): 405-410. doi: 10.1111/j.1750-3841.2009.01291.x.

[3] Alcalá, L., Alonso, C. A., Simón, C., González-Esteban, C., Orós, J., Rezusta, A., Ortega, C., Torres, C. (2016): Wild Birds, Frequent Carriers of Extended-Spectrum $\beta$-Lactamase (ESBL) Producing Escherichia coli of CTX-M and SHV-12 Types. - Microbial Ecology 72(4): 861-869. doi: 10.1007/s00248-015-0718-0. 
[4] Alonso, C. A., Zarazaga, M., Ben Sallem, R., Jouini, A., Ben Slama, K., Torres, C. (2017): Antibiotic resistance in Escherichia coli in husbandry animals: the African perspective. - Letters in Applied Microbiology 64(5): 318-334. doi: 10.1111/lam.12724.

[5] Antonopoulos, D. A., Assaf, R., Aziz, R. K., Brettin, T., Bun, C., Conrad, N., Davis, J. J., Dietrich, E. M., Disz, T., Gerdes, S., Kenyon, R. W., Machi, D., Mao, C., Murphy-Olson, D. E., Nordberg, E. K., Olsen, G. J., Olson, R., Overbeek, R., Parrello, B., Pusch, G. D., Santerre, J., Shukla, M., Stevens, R. L., VanOeffelen, M., Vonstein, V., Warren, A. S., Wattam, A. R., Xia, F. F., Yoo, H. S. (2018): PATRIC as a unique resource for studying antimicrobial resistance. - Briefings in Bioinformatics 20(4): 1094-1102. doi: 10.1093/bib/bbx083.

[6] Benskin, C. McW. H., Wilson, K., Jones, K., Hartley, I. R. (2009): Bacterial pathogens in wild birds: A review of the frequency and effects of infection. - Biological Reviews 84(3): 349-373. doi: 10.1111/j.1469-185X.2008.00076.x.

[7] Benson, D. A., Clark, K., Karsch-Mizrachi, I., Lipman, D. J., Ostell, J., Sayers, E. W. (2015): GenBank. - Nucleic Acids Research 43 (Database issue) D30-5.

[8] Ben Yahia, H., Ben Sallem, R., Tayh, G., Klibi, N., Ben Amor, I., Gharsa, H., Boudabbous, A., Ben Slama, K. (2018): Detection of CTX-M-15 harboring Escherichia coli isolated from wild birds in Tunisia. - BMC Microbiology 18: 26. doi: 10.1186/s12866-018-1163-2.

[9] Bingen, E., Picard, B., Brahimi, N., Mathy, S., Desjardins, P., Elion, J., Denamur, E. (1998): Phylogenetic Analysis of Escherichia coli Strains Causing Neonatal Meningitis Suggests Horizontal Gene Transfer from a Predominant Pool of Highly Virulent B2 Group Strains. - The Journal of Infectious Diseases 177(3): 642-650. doi: $10.1086 / 514217$.

[10] Bonacorsi, P., Clermont, O., Bingen, E. (2000): Rapid and Simple Determination of the Escherichia coli Phylogenetic Group. - Appl Environ Microbiol. 66(10): 4555-4558.

[11] Boyd, D. A., Tyler, S., Christianson, S., McGeer, A., Muller, M. P., Willey, B. M., Bryce, E., Gardam, M., Nordmann, P., Mulvey, M. R. (2004): Complete Nucleotide Sequence of a 92-Kilobase Plasmid Harboring the CTX-M-15 Extended-Spectrum Beta-Lactamase Involved in an Outbreak in Long-Term-Care Facilities in Toronto, Canada. Antimicrobial Agents and Chemotherapy 48(10): 3758-3764. doi: 10.1128/AAC.48.10.3758.

[12] Bradford, P. A. (2001): Extended-Spectrum -Lactamases in the 21st Century: Characterization, Epidemiology, and Detection of This Important Resistance Threat. New York: Clinical Microbiology Reviews, pp. 933-951.

[13] Chantziaras, I., Boyen, F., Callens, B., Dewulf, J. (2014): Correlation between veterinary antimicrobial use and antimicrobial resistance in food-producing animals: A report on seven countries. - Journal of Antimicrobial Chemotherapy 69(3): 827-834. doi: 10.1093/jac/dkt443.

[14] Chen, J., Griffiths, M. W. (1998): PCR differentiation of Escherichia coli from other Gram-negative bacteria using primers derived from the nucleotide sequences flanking the gene encoding the universal stress protein. - Letters in Applied Microbiology 27(6): 369371. doi: 10.1046/j.1472-765X.1998.00445.x.

[15] Clinical and Laboratory Standards Institute (2012): Performance Standards for Antimicrobial Susceptibility Testing; Twenty-Second Informational Supplement. - USA: CLSI M100-S22, Clinical and Laboratory Standards Institute, Wayne, PA, USA.

[16] Collignon, P., Aarestrup, F. M., Irwin, R., McEwen, S. (2013): Human Deaths and ThirdGeneration Cephalosporin use in Poultry, Europe. - Infect. Dis. 19: 1339-1340.

[17] Coque, T. M., Novais, A., Carattoli, A., Poirel, L., Pitout, J., Peixe, L., Baquero, F., Cantón, R., Nordmann, P. (2008): Dissemination of Clonally Related Escherichia coli Strains Expressing. - Emerging Infectious Diseases 14(2): 195-200. 
[18] Croxen, M. A., Law, R. J., Scholz, R., Keeney, K. M., Wlodarska, M., Finlay, B. B. (2013): Recent advances in understanding enteric pathogenic Escherichia coli. - Clinical Microbiology Reviews 26(4): 822-880. doi: 10.1128/CMR.00022-13.

[19] Dashti, A. A., Jadaon, M. M., Abdulsamad, A. M., Dashti, H. (2009): Heat treatment of bacteria: A simple method of DNA extraction for molecular techniques. - Kuwait Medical Journal 41(2): 117-122.

[20] Dereeper, A., Audic, S., Claverie, J-M., Blanc, G. (2010): BLAST-EXPLORER helps you building datasets for phylogenetic analysis. - BMC Evolutionary Biology 10(1): 813. doi: 10.1186/1471-2148-10-8.

[21] EFSA (2010): The European Union Summary Report on antimicrobial resistance in zoonotic and indicator bacteria from humans, animals and food in 2010 European Food Safety Authority European Centre for Disease Prevention and Control. - EFSA Journal, 10233(10310). doi: 10.2903/j.efsa.2012.2598.

[22] Falgenhauer, L., Imirzalioglu, C., Oppong, K., Akenten, C. W., Hogan, B., Krumkamp, R., Poppert, S., Levermann, V., Schwengers, O., Sarpong, N., Owusu-Dabo, E., May, J., Eibach, D. (2019): Detection and characterization of ESBL-producing Escherichia coli from humans and poultry in Ghana. - Frontiers in Microbiology, doi: 10.3389/fmicb.2018.03358.

[23] Forward, K. R., Matheson, K. M., Hiltz, M., Musgrave, H., Poppe, C. (2004): Recovery of cephalosporin-resistant Escherichia coli and Salmonella from pork, beef and chicken marketed in Nova Scotia. - Canadian Journal of Infectious Diseases 15(4): 226-230.

[24] Garcia, B. S. (2014): The Antimicrobial Therapy of the Future: Combating Resistances. Journal of Infectious Diseases and Therapy 02(04): 1-7. doi: 10.4172/23320877.1000146 .

[25] Godambe, L. P., Bandekar, J., Shashidhar, R. (2017): Species specific PCR based detection of Escherichia coli from Indian foods. - 3 Biotech. Springer Berlin Heidelberg 7: 130. doi: 10.1007/s13205-017-0784-8.

[26] Grover, N., Sahni, A. K., Bhattacharya, S. (2013): Therapeutic challenges of ESBLS and Ampc beta-lactamase producers in a tertiary care center. - Medical Journal Armed Forces India 69(1): 4-10. doi: 10.1016/j.mjafi.2012.02.001.

[27] Guenther, S., Grobbel, M., Beutlich, J., Bethe, A., Friedrich, N. D., Goedecke, A., LübkeBecker, A., Guerra, B., Wieler, L. H., Ewers, C. (2010): CTX-M-15-type extendedspectrum beta-lactamases-producing Escherichia coli from wild birds in Germany. Environmental Microbiology Reports 2(5): 641-645. doi: 10.1111/j.17582229.2010.00148.x.

[28] Guenther, S., Aschenbrenner, K., Stamm, I., Bethe, A., Semmler, T., Stubbe, A., Stubbe, M., Batsajkhan, N., Glupczynski, Y., Wieler, L. H., Ewers, C. (2012): Comparable High Rates of Extended-Spectrum-Beta-Lactamase-Producing Escherichia coli in Birds of Prey from Germany and Mongolia. - PLoS ONE 7(12): 1-6. doi: 10.1371/journal.pone.0053039.

[29] Hackman, H. K., Brown, C. A., Twum-Danso, K. (2014): Antibiotic Resistance Profile of CTX-M-type Extended-Spectrum Beta-Lactamases in Escherichia coli and Klebsiella pneumoniae in Accra, Ghana. - Journal of Natural Sciences Research 4(12): 2225-921.

[30] Hansen, T. B., Jensen, T. I., Clausen, B. H., Bramsen, J. B., Finsen, B., Damgaard, C. K., Kjems, J. (2013): Natural RNA circles function as efficient microRNA sponges. - Nature 495: 384-388. doi: 10.1038/nature11993.

[31] Heijnen, L., Medema, G. (2006): Quantitative detection of E. coli, E. coli O157 and other toxin producing $E$. coli in water samples using a culture method combined with real-time PCR. - J Water Health 4: 487-498.

[32] Hudson, C. M., Bent, Z. W., Meagher, R. J., Williams, K. P. (2014): Resistance determinants and mobile genetic elements of an NDM-1-encoding Klebsiella pneumoniae strain. - PLoS ONE 9(6). doi: 10.1371/journal.pone.0099209. 
[33] Huijbers, P. M. C., Graat, E. A. M., Haenen, A. P. J., van Santen, M. G., van EssenZandbergen, A., Mevius, D. J., van Duijkeren, E., van Hoek, A. H. A. M. (2014): Extended-spectrum and AmpC $\beta$-lactamase-producing Escherichia coli in broilers and people living and/or working on broiler farms: Prevalence, risk factors and molecular characteristics. - Journal of Antimicrobial Chemotherapy 69(10): 2669-2675. doi: 10.1093/jac/dku178.

[34] Lazarus, B., Paterson, D. L., Mollinger, J. L., Rogers, B. A. (2015): Do human extraintestinal escherichia coli infections resistant to expanded-spectrum cephalosporins originate from food-producing animals? A systematic review. - Clinical Infectious Diseases 60(3): 439-452. doi: 10.1093/cid/ciu785.

[35] Livermore, D. M., Canton, R., Gniadkowski, M., Nordmann, P., Rossolini, G. M., Arlet, G., Ayala, J., Coque, T. M., Kern-Zdanowicz, I., Luzzaro, F., Poirel, L., Woodford, N. (2007): CTX-M: Changing the face of ESBLs in Europe. - Journal of Antimicrobial Chemotherapy 59(2): 165-174. doi: 10.1093/jac/dkl483.

[36] Martinez-Medina, M., Garcia-Gil, L. J. (2014): Escherichia coli in chronic inflammatory bowel diseases: An update on adherent invasive Escherichia coli pathogenicity. - World Journal of Gastrointestinal Pathophysiology 5(3): 213. doi: 10.4291/wjgp.v5.i3.213.

[37] Paterson, D. L., Bonomo, R. A. (2005): Clinical Update Extended-Spectrum BetaLactamases: a Clinical Update. - Clinical Microbiology Reviews 18(4): 657-686. doi: 10.1128/CMR.18.4.657.

[38] Peirano, G., Asensi, M. D., Pitondo-Silva, A., Pitout, J. D. D. (2011): Molecular characteristics of extended-spectrum $\beta$-lactamase-producing Escherichia coli from Rio de Janeiro, Brazil. - Clinical Microbiology and Infection 17(7): 1039-1043. doi: 10.1111/j.1469-0691.2010.03440.x.

[39] Pinto, L., Radhouani, H., Coelho, C., da Costa, P. M., Simoes, R., Brandao, R. M. L., Torres, C., Igrejas, G., Poeta, P. (2010): Genetic detection of extended-spectrum $\beta$ lactamase-containing escherichia coli isolates from birds of prey from serra da estrela natural reserve in Portugal. - Applied and Environmental Microbiology 76(12): 41184120. doi: 10.1128/AEM.02761-09.

[40] Ramadan, A. A., Abdelaziz, N. A., Amin, M. A., Aziz, R. K. (2019): Novel blaCTX-M variants and genotype-phenotype correlations among clinical isolates of extended spectrum beta lactamase-producing Escherichia coli. - Scientific Reports 9: 4224. doi: 10.1038/s41598-019-39730-0.

[41] Randall, L. P., Clouting, C., Horton, R. A., Coldham, N. G., Wu, G., Clifton-Hadley, F. A., Davies, R. H., Teale, C. J. (2011): Prevalence of Escherichia coli carrying extendedspectrum $\beta$-lactamases (CTX-M and TEM-52) from broiler chickens and turkeys in Great Britain between 2006 and 2009. - Journal of Antimicrobial Chemotherapy 66(1): 86-95. doi: $10.1093 / \mathrm{jac} / \mathrm{dkq} 396$.

[42] Rendón, M. A., Saldana, Z., Erdem, A. L., Monteiro-Neto, V., Vázquez, A., Kaper, J. B., Puente, J. L., Girón, J. A. (2007): Commensal and pathogenic Escherichia coli use a common pilus adherence factor for epithelial cell colonization. - Proceedings of the National Academy of Sciences of the United States of America 104(25): 10637-10642. doi: 10.1073/pnas.0704104104.

[43] Saralaya, V., Chakraborty, A., Adhikari, P., Shenoy, S., Baliga, S., Hegde, A. (2015): Characterization of Escherichia coli phylogenetic groups associated with extraintestinal infections in South Indian population. - Annals of Medical and Health Sciences Research 5(4): 241-246. doi: 10.4103/2141-9248.160192.

[44] Smet, A., Martel, A., Persoons, D., Dewulf, J., Heyndrickx, M., Catry, B., Herman, L., Haesebrouck, F., Butaye, P. (2008): Diversity of extended-spectrum $\beta$-lactamases and class $C \beta$-lactamases among cloacal Escherichia coli isolates in Belgian broiler farms. Antimicrobial Agents and Chemotherapy 52(4): 1238-1243. doi: 10.1128/AAC.0128507 . 
[45] Sorum, H., Sunde, M. (2001): Resistance to antibiotics in the normal flora of animals. Veterinary Research 32(3-4): 227-241.

[46] Stedt, J., Bonnedahl, J., Hernandez, J., Waldenström, J., McMahon, B. J., Tolf, C., Olsen, B., Drobni, M. (2015): Carriage of CTX-M type extended spectrum $\beta$-lactamases (ESBLs) in gulls across Europe. - Acta Veterinaria Scandinavica 57: 74. doi: 10.1186/s13028-015-0166-3.

[47] Sunde, M. (2005): Prevalence and characterization of class 1 and class 2 integrons in Escherichia coli isolated from meat and meat products of Norwegian origin. - Journal of Antimicrobial Chemotherapy 56(6): 1019-1024. doi: 10.1093/jac/dki377.

[48] Todar, K. (2007): Online Textbook of Bacteriology. - Bacterial Endotoxin. [textbookofbacteriology. net/endotoxin. html]. University of Wisconsin-Madison Department of Bacteriology.

[49] Upadhyay, S., Hussain, A., Mishra, S., Maurya, A. P., Bhattacharjee, A., Joshi, S. R. (2015): Genetic environment of plasmid mediated CTX-M-15 extended spectrum betalactamases from clinical and food borne bacteria in north-eastern India. - PLoS ONE 10(9), doi: 10.1371/journal.pone.0138056.

[50] Valentin, L., Sharp, H., Hille, K., Seibt, U., Fischer, J., Pfeifer, Y., Brenner Michael, G., Nickel, S., Schmiedel, J., Falgenhauer, L., Friese, A., Bauerfeind, R., Roesler, U., Imirzalioglu, C., Chakraborty, T., Helmuth, R., Valenza, G., Werner, G., Schwarz, S., Guerra, B., Appel, B., Kreienbrock, L., Kasbohrer, A. (2014): Subgrouping of ESBLproducing Escherichia coli from animal and human sources: an approach to quantify the distribution of ESBL types between different reservoirs. - International journal of medical microbiology 304(7): 805-816. doi: 10.1016/j.ijmm.2014.07.015.

[51] Van den Bogaard, A. E., Stobberingh, E. E. (2000): Epidemiology of resistance to antibiotics: Links between animals and humans. - International Journal of Antimicrobial Agents 14(4): 327-335. doi: 10.1016/S0924-8579(00)00145-X.

[52] Veldman, K., van Tulden, P., Kant, A., Testerink, J., Mevius, D. (2013): Characteristics of cefotaxime-resistant Escherichia coli from wild birds in The Netherlands. - Applied and Environmental Microbiology 79(24): 7556-7561. doi: 10.1128/AEM.01880-13.

[53] Wasiński, B., Rózanska, H., Osek, J. (2013): Occurrence of extended spectrum BLactamaseand AmpC-Producing Escherichia coli in meat samples. - Bulletin of the Veterinary Institute in Pulawy 57(4): 513-517. doi: 10.2478/bvip-2013-0089.

[54] Woodford, N., Fagan, E. J., Ellington, M. J. (2004): Molecular Characterisation of Escherichia Coli Isolates Producing Ctx-M-15 Extended-Spectrum B -Lactamase. Journal of Antimicrobial Chemotherapy 57(1): 154-155.

[55] Yan, J. J., Hong, C. Y., Ko, W. C., Chen, Y. J., Tsai, S. H., Chuang, C. L., Wu, J. J. (2004): Dissemination of blaCMY-2 among Escherichia coli Isolates from Food Animals, Retail Ground Meats, and Humans in Southern Taiwan. - Antimicrobial Agents and Chemotherapy 48(4): 1353-1356. doi: 10.1128/AAC.48.4.1353-1356.2004.

[56] Zeynudin, A., Pritsch, M., Schubert, S., Messerer, M., Liegl, G., Hoelscher, M., Belachew, T., Wieser, A. (2018): Prevalence and antibiotic susceptibility pattern of CTX-M type extended-spectrum $\beta$-lactamases among clinical isolates of gram-negative bacilli in Jimma, Ethiopia. - BMC Infectious Diseases 18: 524. doi: 10.1186/s12879-018-3436-7. 